\title{
Psychometric Properties of the Chinese Version of Copenhagen Burnout Inventory Among Employees in Two Companies in Taiwan
}

\author{
Wan-Yu Yeh, Yawen Cheng, Chiou-Jong Chen, Pei-Yi Hu, and Tage S. Kristensen
}

\begin{abstract}
This study examined the psychometric properties of two selected scales-'personal burnout' and 'work-related burnout'-from the Chinese version of the Copenhagen Burnout Inventory (C-CBI) in 384 employees from two companies in Taiwan. A selfadministered questionnaire was used that included the two C-CBI scales, the scales of mental health, vitality and general health from the Short Form 36 (SF-36), perceived level of job stress, job satisfaction, working hours, as well as measures for psychological job demands, job control, work-related social support, and over-commitment to work. Both the C-CBI personal burnout scale and work-related burnout scale had high internal consistency and were correlated well with other health, job characteristics, and perception of work measures; furthermore, exploratory factor analysis extracted two empirical factors. However, the two C-CBI scales were highly correlated in the present population and appeared to measure overlapping concepts. Some comments and suggestions were raised for further improvement.
\end{abstract}

Key words: validity, reliability, occupational health, burnout, Copenhagen Burnout Inventory (CBI), Taiwan

The problems with excessive workloads and job stress have become major public health concerns in Taiwan. Nationwide surveys conducted by the government indicated that the proportion of workers who reported often or always feeling very stressed at work has increased substantially in recent years-in men from $7.6 \%$ to $19.3 \%$ and in women from $6.5 \%$ to $19.0 \%$ - during the period from 1994 to 2004 (IOSH, 1994, 2004). In recent years, several suspect victims of 'Karoshi' (sudden death from overwork) have caused even greater anxiety. Growing demands from the public for epidemiologic information with regard to the extent, distribution, and major determinants of workrelated burnout have pushed the government to inves-

Wan-Yu Yeh, Institute of Health Policy and Management, College of Public Health, National Taiwan University, Taipei, Taiwan; Yawen Cheng, Institute of Health Policy and Management, College of Public Health, National Taiwan University, Taipei, Taiwan; Chiou-Jong Chen, Institute of Occupational Safety and Health, Council of Labor Affairs, Taipei, Taiwan; Pei-Yi $\mathrm{Hu}$, Institute of Occupational Safety and Health, Council of Labor Affairs, Taipei, Taiwan; Tage S. Kristensen, National Institute of Occupational Health, Copenhagen, Denmark.

This study was supported by the Institute of Occupational Safety and Health, Council of Labor Affairs (IOSH93-M308), and a research grant from the National Science Council (NSC-93-2320B002-083), Taiwan. The authors thank volunteers who kindly agreed to participate in this study.

Correspondence concerning this article should be addressed to Yawen Cheng, ScD, Institute of Health Policy and Management, College of Public Health, National Taiwan University, Taipei, Taiwan. Email: ycheng@ntu.edu.tw tigate these problems further. At this stage, we found it urgent to develop a tool to assess the problem of burnout in the general working population.

We searched existing literature for established measures that could be used for general working population. It turned out that the Maslach Burnout Inventory (MBI) developed by Maslach et al. in the early 1980s has been the most widely used (Maslach \& Johnson, 1986; Schaufeli \& Buunk, 2003). Maslach defined 'burnout' as a syndrome of 'emotional exhaustion,' 'depersonalization,' and 'reduced personal accomplishment,' and the three scales of MBI were designed to measure the three dimensions accordingly. The original form of MBI was designed for professionals in human services sectors, and a recent modification, the MBI-General Survey (MBI-GS), expanded the usage to all employment sectors.

Despite of its authoritative status in this field, however, we were concerned about the applicability of the MBI-GS in our study. Without clear theoretical conceptualization and in-depth qualitative research, we are not certain if the three measures of MBI-GS'general exhaustion,' 'cynicism,' and 'reduced professional efficacy,' which are parallel to those of the original MBI-really reflect the experience of work-related burnout in our culture. Especially, the forms of burnout experiences might differ greatly across occupational groups and socioeconomic categories. For example, the item 'I have become less enthusiastic about my work' is designed to assess the level of 'cynicism.' 
It is plausible that such a measure is more relevant to professionals than, say, assembly line workers who take jobs primarily to make ends meet. Furthermore, the interrelationship of the three MBI subscales is not clear-some studies indicated 'emotional exhaustion' was not correlated with depersonalization or reduced personal accomplishment (Winwood et al., 2003). Although it might be interesting to study different aspects of burnout, in this study we decided to focus on the core concept of burnout, i.e., the status of fatigue and exhaustion.

It appears to us that a more recent developmentthe Copenhagen Burnout Inventory (CBI) - measures the status of burnout in a more straightforward way. Another key feature of the CBI is that it differentiates between domains of burnout. Three forms of burnout are defined according to the life domain from which it may arise, and three sub-scales were constructed accordingly: (1) personal or generic burnout, measuring the degree of physical and psychological exhaustion experienced by the person, regardless of occupational status; (2) work-related burnout, measuring the degree of physical and psychological exhaustion which is perceived by the person as related to work; and (3) clientrelated burnout - measuring the degree of physical and psychological exhaustion which is perceived by the person as related to work with clients (Kristensen et al., 2005).

As a preparation work for a national survey of burnout in general working people in Taiwan, we translated the CBI into Chinese and conducted this pilot study to examine the applicability of the two scales of the Chinese Version of the CBI (C-CBI) personal burnout and work-related burnout-in Taiwanese working people. The internal consistency, construct validity, and criterion-related validity of these two subscales were evaluated. The relationships of burnout with various established job stressors or psychosocial factors, including working hours, job demands, job control, workplace social support, and overcommitment, were also evaluated.

\section{Methods}

\section{Study Population}

Study subjects were from two worksites. One was the headquarters of a state-owned petroleum company (C), and another was the headquarters of a private information technology company $(\mathrm{W})$. Both were located in the Taipei metropolitan area. The size of the workforce of both worksites was about 1,500 employees. Most of these workers were technicians, engineers, managers, other professionals, and white-collar office workers.

To recruit participants for this pilot study, announcements were made to all staff to seek volunteers in the two worksites in September 2004. Questionnaires were handed to volunteers who were asked to return them within a week. A total of 200 questionnaires were handed out at each worksite. Through assistance from companies' staffs, we received 384 effective questionnaires in return $(C=190, W=194)$. The recovery rate was $96 \%$.

\section{Questionnaire}

In this study, only the 'personal burnout' and 'workrelated burnout' subscales of the CBI were translated into Chinese because the remaining subscale 'clientrelated burnout' may not be suitable for all working people. The C-CBI 'personal burnout' and 'work burnout' subscales consist of 6 and 7 items, respectively. Its English version was translated into Chinese by the second author (YC) and pre-tested with several employees to ensure its clarity. Some items were reworded based on feedbacks from these pretests. Afterwards, two bilinguals who were unrelated to this study and blind to the English originals translated these questions back into English. The Chinese back translation was compared with the original items, and some items were modified based on comments and suggestions from the original developer of the CBI (the fourth author in this paper, TSK). (See Appendix for the original CBI items, back-translation, and calculation formula.) (For details of all subscales of the original CBI, see Borritz \& Kristensen, 2001.)

Also included in the questionnaire were items for work characteristics, including average work hours and the three main components of Karasek's DemandControl-Support (DCS) model. This model has been a central piece in the field of job stress research, which postulates that the combination of high psychological work demands, low job control, and poor social support at work causes the greatest job strain. Information regarding the Chinese version of the Job Content Questionnaire (C-JCQ) based on the DCS model can be found elsewhere (Cheng et al., 2003). A subscale for assessment of a particular attitude specified by Siegrist's Effort-Reward Imbalance (ERI) model as 'over-commitment' was also included in the questionnaire (Siegrist et al., 1990; Li et al., 2004). Also adopted were subscales from the Short Form 36, namely mental health (5 items), vitality (4 items), and general health (5 items) (Ware \& Sherbourne, 1992), and a subscale for job satisfaction ( 5 items) adopted from the Job Content Questionnaire (Karasek, 1985; Karasek \& Theorell, 1990; Cheng et al., 2003). For all scales, scores of reversed items were re-ordered in order to make the items additive in the same direction.

\section{Analysis}

Distributions of age, educational level, work characteristics, and health status were summarized and the differences between men and women were tested with 
Chi-square test and ANOVA test. Cronbach's alpha coefficients and Pearson correlation coefficients matrix were used to examine the internal consistency and homogeneity of the C-CBI subscales of 'personal burnout' and 'work burnout.' Exploratory factor analysis was performed to examine the factor structures of all the 13 items for the two C-CBI subscales. In order to understand the relationship between the $\mathrm{C}-\mathrm{CBI}$ and other work-related or health-related measures, Pearson correlation coefficients of C-CBI subscales with work factors, over-commitment, SF-36 subscales, and job satisfaction were examined to check concurrent validity. Moreover, in order to facilitate further comparison between the C-CBI burnout measure and a similar but in opposite direction concept, 'vitality,' we reversed scores of SF-36 vitality subscale and examined its consistency of the two C-CBI burnout measures. The scores of these scales were classified into tertiles, and the consistency was examined.

Analyses were performed in the combined sample of men and women for the sake of increasing statistical power. Stratified analyses were also performed in male and female subgroups to explore potential gender differences. Most results were similar for men and women; therefore, only the combined results are presented in the Tables. All analyses were conducted using SAS 8.2 (SAS Institute, 1999).

\section{Results}

\section{Demographic Information, Work Characteristics, and Health Status}

Table 1 summarizes the demographic information, work characteristics, and health status of the study population. Women accounted for 55\% of the study population, and the mean age (SD) was 39 (10.8) years. Overall, $25 \%$ of the study population had a graduate degree. Men were significantly younger, with a higher educational level, and tended to work longer hours than women in this population. Compared with women, men also reported higher levels of psychological work demands, job control, and over-commitment, and were also more likely to perceive high stress at work. Levels of work-related burnout were found to be significantly higher in men than in women, but there were no significant difference between genders in levels of personal burnout and the SF-36 subscales.

Table 1. Demographic Information, Work Characteristics and Health Status Characteristic

\begin{tabular}{|c|c|c|c|c|c|c|c|c|c|c|}
\hline & \multicolumn{3}{|c|}{ Total sample $(n=384)$} & \multicolumn{3}{|c|}{$\operatorname{Men}(n=174)$} & \multicolumn{3}{|c|}{ Women $(n=210)$} & \multirow[b]{2}{*}{$\begin{array}{l}\text { Gender } \\
\text { diff. }\end{array}$} \\
\hline & $\begin{array}{c}\text { n or } \\
\text { mean }\end{array}$ & $\begin{array}{l}(\%) \text { or } \\
(\text { sd) }\end{array}$ & $\alpha$ & $\begin{array}{l}(n \text { or }) \\
\text { mean }\end{array}$ & $\begin{array}{l}(\%) \text { or } \\
(\text { sd) }\end{array}$ & $\alpha$ & $\begin{array}{c}n \text { or } \\
\text { mean }\end{array}$ & $\begin{array}{l}(\%) \text { or } \\
(\text { sd) }\end{array}$ & $\alpha$ & \\
\hline \multicolumn{11}{|l|}{ Age } \\
\hline Mean age (range 21-64) & 39.0 & $(10.8)$ & & 37.5 & $(10.5)$ & & 40.4 & $(10.9)$ & & $* *$ \\
\hline Age group (years) & & & & & & & & & & $*$ \\
\hline $21-30$ & 113 & $(30.1 \%)$ & & 63 & $(36.2 \%)$ & & 50 & $(24.9 \%)$ & & \\
\hline $31-40$ & 106 & $(28.3 \%)$ & & 54 & $(31.0 \%)$ & & 52 & $(25.9 \%)$ & & \\
\hline $41-50$ & 82 & $(21.9 \%)$ & & 32 & $(18.4 \%)$ & & 50 & $(24.9 \%)$ & & \\
\hline $51-64$ & 74 & $(19.7 \%)$ & & 25 & $(14.4 \%)$ & & 49 & $(24.4 \%)$ & & \\
\hline Education level & & & & & & & & & & $* * *$ \\
\hline Below high school & 65 & $(17.1 \%)$ & & 5 & $(2.9 \%)$ & & 60 & $(29.0 \%)$ & & \\
\hline University & 220 & $(57.7 \%)$ & & 102 & $(58.6 \%)$ & & 118 & $(57.0 \%)$ & & \\
\hline Graduate & 96 & $(25.2 \%)$ & & 67 & $(38.5 \%)$ & & 29 & $(14.0 \%)$ & & \\
\hline $\begin{array}{l}\text { Mean work hours (per week) } \\
\quad \text { (range } 4-126)\end{array}$ & 45.4 & $(9.6)$ & & 48.6 & $(11.2)$ & & 42.6 & $(6.9)$ & & $* * *$ \\
\hline \multicolumn{11}{|l|}{ C-JCQ } \\
\hline Demand (range 26-58) & 43.2 & $(4.3)$ & .70 & 44.1 & $(4.8)$ & .74 & 42.4 & $(3.8)$ & .62 & $* * *$ \\
\hline Control (range 44-88) & 65.7 & $(7.6)$ & .72 & 68.2 & $(7.5)$ & .68 & 63.6 & $(7.1)$ & .69 & $* *$ \\
\hline Support (range 13-32) & 23.8 & $(3.0)$ & .84 & 23.9 & $(3.2)$ & .85 & 23.7 & $(2.8)$ & .84 & \\
\hline $\begin{array}{l}\text { Perceived work stress } \\
\text { ("Always", "Usually") }\end{array}$ & 84 & $(21.9 \%)$ & & 54 & $(31.0 \%)$ & & 30 & $(14.3 \%)$ & & $* * *$ \\
\hline \multicolumn{11}{|l|}{ ERI } \\
\hline Over-commitment (range 8-24) & 15.3 & $(2.7)$ & .77 & 15.6 & $(2.8)$ & .77 & 15.0 & $(2.6)$ & .78 & $*$ \\
\hline \multicolumn{11}{|l|}{ C-CBI score ${ }^{a}$} \\
\hline Personal burnout (range 0-100) & 45.0 & $(17.1)$ & .93 & 45.3 & $(17.6)$ & .94 & 44.7 & $(16.6)$ & .93 & \\
\hline Work burnout (range 0-100) & 36.8 & $(15.6)$ & .87 & 38.6 & $(16.1)$ & .88 & 35.4 & $(15.2)$ & .86 & $*$ \\
\hline \multicolumn{11}{|l|}{ SF-36 } \\
\hline Mental health (range 0-100) & 61.5 & $(14.3)$ & .82 & 60.6 & $(15.4)$ & .85 & 62.2 & $(13.3)$ & .77 & \\
\hline Vitality (range 0-100) & 56.1 & $(15.3)$ & .78 & 55.6 & $(16.3)$ & .83 & 56.5 & $(14.4)$ & .73 & \\
\hline General health (range 0-100) & 59.0 & $(18.8)$ & .82 & 58.7 & $(19.4)$ & .83 & 59.3 & $(18.4)$ & .73 & \\
\hline Mean job satisfaction (range 5-100) & 61.1 & $(16.7)$ & .75 & 60.5 & $(15.5)$ & 69 & 61.6 & $(17.7)$ & .79 & \\
\hline
\end{tabular}

${ }^{*} p<0.05 ; * * p<0.01 ; * * * p<0.001$.

${ }^{a}$ All items of CBI were kept in calculation. 
Table 2. Correlation Matrix for the C-CBI Personal Burnout and Work Burnout Items (Pearson Correlation Coefficient) $(\mathrm{N}=384)$

\begin{tabular}{|c|c|c|c|c|c|c|c|c|c|c|c|c|c|}
\hline & \multicolumn{6}{|c|}{ Personal Burnout } & \multicolumn{7}{|c|}{ Work Burnout } \\
\hline & (1) & (2) & (3) & (4) & (5) & (6) & (7) & (8) & (9) & (10) & (11) & (12) & (13) \\
\hline \multicolumn{14}{|l|}{ Personal burnout } \\
\hline (1) Tired & 1 & & & & & & & & & & & & \\
\hline (2) Physical & $.77 * * *$ & 1 & & & & & & & & & & & \\
\hline (3) Emotional & $.67 * * *$ & $.71 * * *$ & 1 & & & & & & & & & & \\
\hline (4) Can't take & $.57 * * *$ & $.65^{* * *}$ & $.74 * * *$ & 1 & & & & & & & & & \\
\hline (5) Worn out & $.68 * * *$ & $.74 * * *$ & $.71 * * *$ & $.77 * * *$ & 1 & & & & & & & & \\
\hline (6) Weak & $.62 * * *$ & $.66^{* * *}$ & $.61 * * *$ & $.68 * * *$ & $.74 * * *$ & 1 & & & & & & & \\
\hline \multicolumn{14}{|l|}{ Work burnout } \\
\hline (7) Work emotion & $.51 * * *$ & $.59 * * *$ & $.67 * * *$ & $.63 * * *$ & $.62 * * *$ & $.59 * * *$ & 1 & & & & & & \\
\hline (8) Work burnout & $.54 * * *$ & $.63^{* * *}$ & $.65 * * *$ & $.66 * * *$ & $.65^{* * *}$ & $.61 * * *$ & $.77 * * *$ & 1 & & & & & \\
\hline (9) Work frustrate & $.39 * * *$ & $.45^{* * *}$ & $.54 * * *$ & $.56 * * *$ & $.47 * * *$ & $.45^{* * *}$ & $.64 * * *$ & $.64 * * *$ & 1 & & & & \\
\hline $\begin{array}{l}\text { (10) Exhausted at } \\
\text { the end }\end{array}$ & $.60 * * *$ & $.67 * * *$ & $.63 * * *$ & $.62 * * *$ & $.68 * * *$ & $.61 * * *$ & $.60 * * *$ & $.66^{* * * *}$ & $.53 * * *$ & 1 & & & \\
\hline $\begin{array}{l}\text { (11) Exhausted at } \\
\text { the starting }\end{array}$ & $.44 * * *$ & $.53 * * *$ & $.54 * * *$ & $.56 * * *$ & $.58 * * *$ & $.52 * * *$ & $.59 * * *$ & $.61 * * *$ & $.56 * * *$ & $.65 * * *$ & 1 & & \\
\hline $\begin{array}{l}\text { (12) Tiring work } \\
\text { hours }\end{array}$ & $.36 * * *$ & $.43 * * *$ & $.46 * * *$ & $.53 * * *$ & $.47 * * *$ & $.49 * * *$ & $.51 * * *$ & $.54 * * *$ & $.55^{* * * *}$ & $.48 * * *$ & $.68 * * *$ & 1 & \\
\hline $\begin{array}{l}\text { (13) Energy for } \\
\text { others }\end{array}$ & $.16^{* *}$ & $.20 * * *$ & $.19 * * *$ & $.16^{* * *}$ & $.19 * * *$ & $.19 * * *$ & $.19 * * *$ & $.19 * * *$ & $.19 * * *$ & .09 & $.18 * * *$ & $.16^{* * *}$ & 1 \\
\hline
\end{tabular}

\section{Internal Consistency of the C-CBI}

Cronbach's alpha coefficients for all subscales of C-CBI, JCQ, ERI, and SF-36 are also shown in Table 1. Both the C-CBI personal and work burnout subscales exhibit high internal consistency, with Cronbach's alpha coefficients higher than 0.86 in both men and women subgroups. The Pearson correlation between the scores for 'personal burnout' and 'work burnout' was 0.78 , indicating that these two scales were considerably correlated burnout constructs. Table 2 shows the correlation matrix of all the 13 items of C-CBI. A single reversed item (item 13) was reordered in calculation. Most of the correlations among items had coefficient values above 0.5 , indicating high inter-item correlation within and between the two subscales. Within-subscale correlations were slightly higher than cross-subscale correlations. However, item 13 (energy for others) correlated poorly with all the other items. When stratified by gender, we found that item 13 was weakly correlated with most of the other items in men, but in women item 13 was not correlated with any of the other items at a level of statistical significance (data not shown).

\section{Construct Validity of the C-CBI}

Table 3 presents the results of exploratory factor analysis for the C-CBI items. With principal component and Promax rotation methods, two factors were extracted that had an eigenvalue above 1.0. All of the 6 items for the 'personal burnout' subscale loaded on the first factor, in addition to 3 items-item 7 (work emotion), item 8 (work burnout) and item 10 (exhausted at the end) from the 'work burnout' subscale. Items for the 'work burnout' subscale loaded on the second factor, except item 10 (exhausted at the end). Items 7 (work emotion) and 8 (work burnout) showed double loading in both factors. The first factor contained a disproportionately larger share of the total variation than factor 2 (59\% vs. $8 \%)$. It is also noteworthy that

Table 3. Exploratory Factor Analysis of C-CBI: Factor Loadings from the Rotated Factor Pattern Matrix ${ }^{a}$

\begin{tabular}{llc}
\hline & \multicolumn{2}{l}{ Total sample $(\boldsymbol{n}=\mathbf{3 8 4})$} \\
\cline { 2 - 3 } C-CBI Subscale Items & F1 & F2 \\
\hline Personal burnout & & \\
(1) Tired & .99 & \\
(2) Physical & .94 & \\
(3) Emotional & .77 & \\
(4) Can't take & .67 & \\
(5) Worn out & .87 & \\
(6) Weak & .77 & .49 \\
Work burnout & & .79 \\
(7) Work emotion & .40 & \\
(8) Work burn out & .45 & .72 \\
(9) Work frustrate & & .84 \\
(10) Exhausted at the end & .66 \\
(11) Exhausted at the starting & & .42 \\
(12) Tiring work hours & & $8 \%$ \\
(13) Energy for others & & \\
Variance explained by each factor $(\%)$ & $59 \%$ & \\
\hline
\end{tabular}

${ }^{a}$ Listing only items with factor loading $\geq 0.30$. 
in men item 13 (factor loading $=0.85$ ) loaded on the same factor as the items of the 'work burnout' subscale, while in women, item 13 (factor loading $=0.58$ ) loaded on the factor of the 'personal burnout' subscale (full results not shown).

When examining the factor pattern of all the $13 \mathrm{CBI}$ items in Table 3, we found that there seemed to be a difference between the items that load only on the second factors (i.e., items 9, 11, 12, and 13) and the rest. Especially items 9 (work frustrate), 11 (exhausted at the starting), and 12 (tiring work hours) seemed to reflect a certain frustration and aversion toward work, while the rest items refer to exhaustion in a more general sense. We divided the 7 items of the 'work burnout' subscale into two groups based on the factor pattern revealed in Table 3. The first group (items 7, 8, 10) refers to 'work exhaustion' and the second group refers to 'work frustration' (items 9, 11, 12, and 13). The correlation coefficient between the scores of 'work exhaustion' and 'work frustration' was 0.7 . When the scores of the two measures were correlated with the three C-JCQ work characteristic subscales, we found that lower levels of job control were significantly associated with higher levels of 'work frustration' ( $r=-0.18, p \leq 0.01)$, but not associated with 'work exhaustion' ( $r=0.03, p=$ $0.6)$. In addition, heavier job demands were found to be associated more strongly with 'work exhaustion' ( $r=$ $0.46, p \leq 0.01)$ than 'work frustration' $(r=0.29, p \leq$ $0.01)$, while lower workplace social support was correlated to a greater extent with 'work frustration' ( $r=$ $-0.21, p \leq 0.01)$ than 'work exhaustion' $(r=-0.15$, $p \leq 0.01)$.

\section{Concurrent Validity of the C-CBI}

As shown in Table 4, long working hours, psychological work demands, and over-commitment were associated with higher levels in both of the C-CBI

Table 4. Correlations of the C-CBI Subscales with Burnout-related Factors (Pearson Correlation Coefficient $)(\mathrm{n}=384)$

\begin{tabular}{lrr}
\hline & \multicolumn{2}{c}{ C-CBI Subscales } \\
\cline { 2 - 3 } Other Burnout-related Scales & $\begin{array}{r}\text { Personal } \\
\text { Burnout }\end{array}$ & $\begin{array}{c}\text { Work } \\
\text { Burnout }\end{array}$ \\
\hline Working hours per week & $.23 * * *$ & $.22 * * *$ \\
C-JCQ-Psychological Work Demands & $.43 * * *$ & $.41 * * *$ \\
C-JCQ-Job Control & $-.03 * * *$ & $-.08 * * *$ \\
C-JCQ-Workplace Social Support & $-.13 * * *$ & $-.20 * * *$ \\
ERI-Over-commitment & $.57 * * *$ & $.59 * * *$ \\
SF36-Mental health & $-.65 * * *$ & $-.63 * * *$ \\
SF36-Vitality & $-.67 * * *$ & $-.56 * * *$ \\
SF36-General health & $-.57 * * *$ & $-.45 * * *$ \\
Job satisfaction & $-.25 * * *$ & $-.32 * * *$ \\
\hline
\end{tabular}

$* p<0.05 ; * * p<0.01 ; * * * p<0.001$.
Table 5. Cross-tabulation between the Scores for C-CBI and $S F-36$ Vitality ${ }^{a}$

\begin{tabular}{|c|c|c|c|c|c|c|}
\hline & \multicolumn{6}{|c|}{ SF-36 Vitality_Rev ${ }^{a}$} \\
\hline & \multicolumn{2}{|c|}{ Low } & \multicolumn{2}{|c|}{ Med } & \multicolumn{2}{|r|}{ High } \\
\hline \multicolumn{7}{|c|}{ C-CBI: Personal burnout ${ }^{\mathrm{b}}$} \\
\hline Low & 77 & $(20.3 \%)$ & 34 & $(9.0 \%)$ & 6 & $(1.6 \%)$ \\
\hline Med & 36 & $(9.5 \%)$ & 53 & $(14.0 \%)$ & 13 & $(3.4 \%)$ \\
\hline High & 13 & $(3.4 \%)$ & 76 & $(20.1 \%)$ & 71 & $(18.7 \%)$ \\
\hline \multicolumn{7}{|c|}{ C-CBI: Work burnout ${ }^{\mathrm{c}}$} \\
\hline Low & 62 & $(16.1 \%)$ & 23 & $(6.1 \%)$ & 9 & $(2.4 \%)$ \\
\hline Med & 50 & $(13.2 \%)$ & 70 & $(18.8 \%)$ & 29 & $(7.7 \%)$ \\
\hline High & 15 & $(4.0 \%)$ & 69 & $(18.2 \%)$ & 52 & $(13.7 \%)$ \\
\hline
\end{tabular}

${ }^{a}$ Reverse ordering of the item for scoring.

${ }^{b}$ The percentage of perfect matches (between CBI personal burnout and SF-36 vitality): $53.0 \%$

${ }^{c}$ The percentage of perfect matches (between CBI work burnout and SF-36 vitality): $48.5 \%$.

burnout measures. In addition, higher levels of C-CBI burnout measures were found to correlate with poor health, as assessed by the three SF-36 subscales, and lower level of job satisfaction. The correlations with SF-36 health status were stronger for the C-CBI 'personal burnout' than 'work burnout' subscale, while the correlations with job satisfaction were stronger for 'work burnout' than 'personal burnout' subscale. Workplace social support correlated negatively with the C-CBI 'work burnout' subscale, while there was no association between the two C-CBI measures and job control.

Scores of the two C-CBI measures and SF-36 vitality were first ranked and participants were divided equally into three categories (low, medium, and high). Because some respondents had same scale scores, the classification did not generate an equal sample size for each tertile. Cross-tabulations of the two C-CBI measures and the reverse score of SF-36 vitality were shown in Table 5 . The results suggested moderate consistency. For the C-CBI 'personal burnout' subscale, the percentages of being perfectly matched, partially matched, and completely unmatched with the reverse score of SF-36 vitality were $53 \%, 42 \%$, and $5 \%$, respectively; while for the C-CBI 'work burnout' subscale, the percentages were $49 \%, 45 \%$, and $6 \%$, respectively.

\section{Discussion}

The findings of this study indicated that the psychometric properties of the Chinese version of the two CBI subscales were satisfactory. Cronbach's alpha coefficients for both C-CBI subscales were well above 0.86 , indicating a high level of internal consistency. The C-CBI burnout measures also correlated well with burnout related factors in expected directions, 
including working hours, psychological work demands, over-commitment to work, mental health, vitality, general health, and job satisfaction, indicating consistency in concurrent validity. There were some concerns with regard to the C-CBI, however. First, item correlation analysis and factor analysis suggested that items from the two C-CBI 'personal burnout' and 'work burnout' subscales were highly correlated and the two measures shared overlapping concept. The two C-CBI subscales seem to measure much the same in the present population of employees. The main difference is that the former is a generic measure designed to assess the general status of a person's fatigue and exhaustion, while the latter is designed to assess the degree of fatigue and exhaustion which is perceived by the person as related to work. Because our study subjects were mostly full-time working people whose average working hours were 45 hours per week, it could be expected that work constituted a central part of life, and experience at work can hardly be differentiated from other domains of life. In a recent study of Danish population (Kristensen et al., 2005), personal burnout and work burnout were also found to be highly correlated $(r=0.72, p<0.01)$. Nevertheless, there are counter arguments that supported the use of separated measures of generic burnout and work burnout. Theoretically, it is hypothesized that people who are high on one of the two measures and low on the other may behave in distinct ways. For example, workaholic people may feel tired in daily life but not tired of their work. while disengaged people may feel tired of their work but not tired when they get off work. Some studies have provided empirical evidences supporting the differentiation of the three distinct domains of the CBI. For example, in a follow-up study of Danish workers, deterioration in work burnout over time was found, but not in personal burnout or client burnout (Borritz et al., 2005). In the same study, different aspects of work characteristics were also found to predict work-related burnout and client-related burnout differently over time.

The factor structure of the CBI items suggested that there seemed to be different dimensions in workrelated burnout. For example, experiences of frustration at work or consequential aversion toward work might be a distinguishable form of work-related burnout. In the present study, we found that lower levels of job control were associated with 'work frustration,' but not with general work exhaustion. Besides, job demands were found to be correlated with 'work exhaustion' to a greater extent than with 'work frustration,' while low in workplace social support was correlated with 'work frustration' to a greater extent than 'work exhaustion.' These findings suggested that different forms of work-related burnout should be specified in order to improve our understanding about the nature of burnout in the workplace.
When looking into the correlation matrix for all the C-CBI items, we found that item 13 'Do you have enough energy for family and friends during leisure time?' correlated poorly with the other items. Besides, factor loading for this item was also low in exploratory factor analysis. When analyses were performed without item 13, we found that the results of Pearson correlations and exploratory factor analyses were quite similar to analyses with all the 13 items. Because the rest of the C-CBI items were asked with similar response formats in the same direction, we suspected that it might produce stereotype responses, such as a tendency to mark response choices on the right-hand side or those on the left-hand side consistently, so that item 13, the only item with an opposite direction and also the last item in the C-CBI, was left out of the pattern. When examining the patterns of responses, we found only $8.2 \%$ participants (31 out of 380) showing such a problem (i.e., answering 'seldom' or 'never' for all the 13 items or vise versa). Thus, we recommend that this item should be deleted in future use of the Chinese version of the CBI. In addition, an item with an opposite direction should be used in order to avoid potential stereotyped responses.

Another problem is that item 13 poses a strong assumption that people always have intentions and chances to meet friends and families. For those who are socially isolated or prefer to be in solitude, this question may be irrelevant. It also assumes that people have an enjoyable family life, but it may not be always true. For example, for many working women who are taking on a second shift as a family housekeeper and caretaker, there is virtually no 'leisure time.' For those who are overloaded with multiple social roles, social interactions may imply other kinds of duties. Interestingly, we found that item 13 loaded on the same factor with items of work-related burnout in men, but it loaded on the same factor with items of personal burnout in women. These findings suggested that item 13 seemed to capture work-related burnout to a greater extent in men, while in women it was associated with general burnout status. Taking into consideration that there are dramatic gender differences in social role expectation toward paid work and family care work, we suspect that men and women might have comprehended this question differently. Following the same line of thought, the C-CBI 'work burnout' subscale as a whole fails to take into account the influences of family workloads and, especially, gender differences in family workloads and social expectation. For example, item 8 'Do you feel burnout because of your work?' implies causality that we are asking subjects to judge. One may wonder how differences in social role outside of work can complicate people's judgment with regard to causality of burnout. Nevertheless, our empirical analyses did not indicate that women and men responded to this question differentially. We suggest the development of a 
scale for the measurement of 'family-related burnout' in the future in order to capture the effects of the double workload of women.

Some minor questions arose during the process of translation and in pre-tests. Item 7 'Is your work emotionally exhausting?' is originally designed to assess the nature of work, but in our pretests we found that people tended to answer this question based on their own experiences. It might be more appropriate to ask 'Does your work make you feel emotionally exhausted?' For questions 10-13, we suggest rewording the questions by asking 'how often do you ...' in order to match the response choices.

It should be noticed that in our pretests, some participants commented that several items appeared to be repetitive, for example, item 5 ' $\mathrm{How}$ often do you feel tired out?', item 2 'How often do you feel physically exhausted?', and item 3 'How often do you feel psychologically exhausted?' Especially, many participants had problems distinguishing the differences between physical exhaustion (item 2) and psychological exhaustion (item 3). This may due to culture differences in expression of personal distress. Studies have found that Chinese people tended to express their personal distress with somatic problems and from a psycholinguistic point of view; researchers have found that the vocabulary for physical complaints substantially outnumbers that for emotional and psychological distress (Kleiman, 1986). During the process of translation, we also found that it was hard to appropriate words for different expression of burnout, and the terms 'tired,' 'physically exhausted,' 'psychologically exhausted,' and 'worn-out' all sounded the same in our language. The cultural differences in expression of burnout should be considered in future studies.

Despite of the problems discussed above, we still consider it a strength of the CBI that it assesses exclusively the status of fatigue and exhaustion and does not confuse the experiences of burnout with other components such as coping strategies as the traditional measurement tool MBI. Because the core concept of burnout - a status of energy depletion - is clearly defined and measured, the relationships of burnout with causal factors can be more easily clarified, so as to enhance the abilities for intervention.

So far, only few studies have utilized the CBI and reported its psychometric properties. One of them was the PUMA study of employees in the human service sectors in Denmark (Kristensen et al., 2005). The mean scores of 'personal burnout' and 'work burnout' in our study (45.0 and 36.7) were significantly higher than that in the PUMA study (35.9 and 33.0), but Cornbach's alpha coefficients for both the CBI subscales were in the same range, and the values of correlation coefficients between CBI burnout measures and SF36 vitality scale were similar. The mean scores of the
CBI 'personal' and 'work burnout' subscales in our study were also higher than that found in another study of 312 Australian dental practitioners (40.9 and 36.6) (Winwood et al., 2003; Winwood \& Winefield, 2004). Further comparison is limited because of the potential differences in, and lack of information on, work conditions and social context. In the present study, we found that men worked for longer hours, perceived a higher level of job stress, and also had a significantly higher level of 'work-related burnout' as compared with women. However, it is difficult to generalize our findings to other populations. Without information regarding the nature of work and the surrounding social context, it is not possible to make direct comparisons of our findings with that from other working populations.

This study has some limitations. First, due to the small sample size, our study power might be limited. In addition, because our study subjects were volunteers, we were not certain whether or not non-volunteers would respond to the questionnaire the same way as volunteers. Furthermore, this study was conducted in two worksites, with a workforce of a relatively high educational level. Whether our findings could be generalized to other work sectors and socio-economic groups is also questionable.

In conclusion, the results of this pilot study suggest that the Chinese version of the CBI 'personal burnout' and 'work burnout' subscales have high internal consistency and correlate well with other burnout related factors. We also raise some suggestions for future improvements of the instrument.

\section{References}

Borritz, M., \& Kristensen, T. S. (2001). Copenhagen Burnout Inventory: Normative data from a representative Danish population on personal burnout and results from the PUMA study on personal burnout, work burnout, and client burnout. Retrieved January 13, 2005, from http://www.ami.dk/upload/ udgivelser/cbi_data_uk.pdf

Borritz, M., Bultmann, U., Rugulies, R., Christensen, K. B., Villadsen, E., \& Kristensen, T. S. (2005). Psychosocial work characteristics as predictors for burnout: Findings from 3-year follow up of the PUMA study. Journal of Occupational and Environmental Medicine, 47(10), 1015-1025.

Cheng, Y., Luh, W.-M., \& Guo, Y.-L. (2003). Reliability and validity of the Chinese version of the job content questionnaire in Taiwanese workers. International Journal of Behavioral Medicine, 10(1), 15-30.

Institute of Occupational Safety and Health (IOSH) (1994). Survey of employee's perceptions of safety and health in the work environment. Taipei, Taiwan: The Council of Labor Affairs Institute of Occupational Safety and Health.

Institute of Occupational Safety and Health (IOSH) (2004). Taiwan labor's job-burnout and related psychosocial factor survey in 2004. Taipei, Taiwan: The Council of Labor Affairs Institute of Occupational Safety and Health.

Karasek, R. (1985). Job content instrument questionnaire and user's guide, version 1.1. Los Angeles: University of Southern California. 
Karasek, R., \& Theorell, T. (1990). Healthy work. Stress, productivity, and the reconstruction of working life. New York: Basic Books.

Kleinman, A. (1986). Social origins of distress and disease: Depression, neurasthenia, and pain in modern China. New Haven and London: Yale University Press.

Kristensen, T. S., Borritz, M., Villadsen, E., \& Christensen, K. B. (2005). The Copenhagen burnout inventory. A new tool for the assessment of burnout. Work \& Stress, 19(3), 192-207.

Li, J., Yang, W., Cheng, Y., Siegrist, J., \& Cho, S.-I. (2004). The reliability and validity of the Chinese version of effort-reward imbalance questionnaire among health care workers: A validation study. International Archives of Occupational and Environmental Medicine, 78(3), 198-204.

Maslach, C., \& Johnson, S. (1986). MBI: Maslach burnout inventory: Manual research edition. Palo Alto, CA: University of California, Consulting Psychologists Press.

SAS Institute, Inc. (1999). Statistical analyses system. Version 8.2. North Carolina: Cary.
Schaufeli, W., \& Buunk, B. (2003). Burnout: An overview of 25 years of research and theorizing. In M. Schabracq, J. Winnubst, \& C. Cooper (Eds.), Handbook of work and health psychology (pp. 383-429), West Sussex, UK.: Wiley.

Siegrist, J., Peter, R., Junge, A., Cremer, P., \& Seidel, D. (1990). Low status control, high effort at work and ischemic heart disease: Prospective evidence from blue-collar men. Social Science and Medicine, 31, 1127-1134.

Ware, J. E., \& Sherbourne, C. D. (1992). The MOS 36-item shortform health survey (SF-36). I. Conceptual framework and item selection. Medical Care, 30, 473-483.

Winwood, P. C., \& Winefield, A. H. (2004). Comparing two measures of burnout among dentists in Australia. International Journal of Stress Management, 11(3), 282289.

Winwood, P. C., Winefield, A. H., \& Lushington, K. (2003). The role of occupational stress in the maladaptive use of alcohol by dentists: A study of south Australian general dental practitioners. Australian Dental Journal, 48(2), 102-109.

Appendix. Original, abbreviated forms, the Chinese version and the Chinese Back Translation of the 13 items for the CBI "personal burnout" and "work-related burnout" subscales

\begin{tabular}{|c|c|c|}
\hline Item & Original CBI (Abbreviated forms) & The Chinese version and Back translation \\
\hline 1. & How often do you feel tired? (Tired) ${ }^{1}$ & How often do you feel tired? \\
\hline 2. & How often are you physically exhausted? (Physical) ${ }^{1}$ & How often do you feel physically exhausted? \\
\hline 3. & How often are you emotionally exhausted? (Emotional) ${ }^{1}$ & How often do you feel emotionally exhausted? \\
\hline 4. & How often do you think: "I can't take it anymore?" (Can't take) ${ }^{1}$ & How often do you feel "I can not take it anymore!"? \\
\hline 5. & How often do you feel worn out? (Worn out) ${ }^{1}$ & How often do you feel tired out? \\
\hline 6. & How often do you feel weak and susceptible to illness? (Weak) ${ }^{1}$ & $\begin{array}{l}\text { How often do you feel weak as if you are coming down with } \\
\text { illness? }\end{array}$ \\
\hline 7. & Is your work emotionally exhausting? (Work emotion) ${ }^{2}$ & Is your work emotionally exhausting? \\
\hline 8. & Do you feel burnt out because of your work? (Work burnout) ${ }^{2}$ & Does your work make you feel burned out? \\
\hline 9. & Does your work frustrate you? (Work frustrate) ${ }^{2}$ & Do you feel frustrated with work? \\
\hline 10. & Do you feel worn out at the end of the working day? (Work end) ${ }^{1}$ & After a day of work, do you feel exhausted? \\
\hline 11. & $\begin{array}{l}\text { Are you exhausted in the morning at the thought of another day at } \\
\text { work? (Exhausted morning) }{ }^{1}\end{array}$ & $\begin{array}{l}\text { Do you feel tired just thinking about starting another day of } \\
\text { work? }\end{array}$ \\
\hline 12. & $\begin{array}{l}\text { Do you feel that every working hour is tiring for you? (Tiring } \\
\text { work) }{ }^{1}\end{array}$ & Do you feel that every moment at work is hard? \\
\hline $13 .^{3}$ & $\begin{array}{l}\text { Do you have enough energy for family and friends during leisure } \\
\text { time?(Energy for others) }{ }^{1}\end{array}$ & $\begin{array}{l}\text { Do you have enough energy to spend time with family or } \\
\text { friends while not working? }\end{array}$ \\
\hline
\end{tabular}

${ }^{1}$ Five-point Likert scale: always, often, sometimes, seldom, never/almost never.

${ }^{2}$ Five-point Likert scale: to a very high degree, to a high degree, somewhat, to a low degree, to a very low degree.

${ }^{3}$ Reverse ordering of the item for scoring.

Scoring: Always/ To a very high degree: 100. Often/ To a high degree: 75. Sometimes/ Somewhat: 50 . Seldom/ To a low degree: 25 . Never, almost never/ To a very low degree: 0 .

Personal burnout $=(\mathrm{Q} 1+\mathrm{Q} 2+\mathrm{Q} 3+\mathrm{Q} 4+\mathrm{Q} 5+\mathrm{Q} 6) / 6$.

Work-related burnout $=(\mathrm{Q} 7+\mathrm{Q} 8+\mathrm{Q} 9+\mathrm{Q} 10+\mathrm{Q} 11+\mathrm{Q} 12+\mathrm{Q} 13) / 7$. 